\title{
Large Soluble Oligomers of Amyloid $\beta$-Protein from Alzheimer Brain Are Far Less Neuroactive Than the Smaller Oligomers to Which They Dissociate
}

\author{
Ting Yang, Shaomin Li, -Huixin Xu, Dominic M. Walsh, and Dennis J. Selkoe \\ Ann Romney Center for Neurologic Diseases, Department of Neurology, Brigham and Women's Hospital, Harvard Medical School, Boston, Massachusetts \\ 02115
}

Soluble oligomers of amyloid $\beta$-protein $(\mathrm{oA} \beta)$ isolated from the brains of Alzheimer's disease (AD) patients have been shown experimentally (in the absence of amyloid plaques) to impair hippocampal synaptic plasticity, decrease synapses, induce tau hyperphosphorylation and neuritic dystrophy, activate microglial inflammation, and impair memory in normal adult rodents. Nevertheless, there has been controversy about what types of oligomers actually confer these AD-like phenotypes. Here, we show that the vast majority of soluble $\mathrm{A} \beta$ species obtained from brains of humans who died with confirmed AD elute at high molecular weight (HMW) on nondenaturing size-exclusion chromatography. These species have little or no cytotoxic activity in several bioassays. However, incubation of HMW oA $\beta$ in mildly alkaline buffer led to their quantitative dissociation into low molecular weight oligomers $(\sim 8-70 \mathrm{kDa})$, and these were now far more bioactive: they impaired hippocampal LTP, decreased neuronal levels of $\beta 2$-adrenergic receptors, and activated microglia in wt mice in vivo. Thus, most soluble $\mathrm{A} \beta$ assemblies in $\mathrm{AD}$ cortex are large and inactive but under certain circumstances can dissociate into smaller, highly bioactive species. Insoluble amyloid plaques likely sequester soluble HMW oligomers, limiting their potential to dissociate. We conclude that conditions that destabilize HMW oligomers or retard the sequestration of their smaller, more bioactive components are important drivers of $\mathrm{A} \beta$ toxicity. Selectively targeting these small, cytotoxic forms should be therapeutically beneficial.

Key words: $\beta 2$-adrenergic receptor; $\mathrm{A} \beta$ aggregation; Alzheimer's; long-term potentiation; microglia activation; size-exclusion chromatography

\section{Significance Statement}

Oligomers of amyloid $\beta$-protein $(\mathrm{oA} \beta)$ are tought to play an important role in Alzheimer's disease (AD), but there is confusion and controversy about what types and sizes of oligomers have disease-relevant activity. Using size-exclusion chromatography and three distinct measures of bioactivity, we show that the predominant forms of $A \beta$ in aqueous extracts of $A D$ brain are high molecular weight (HMW) and relatively inactive. Importantly, under certain conditions, the abundant HMW oA $\beta$ can dissociate into low molecular weight species, and these low molecular weight oligomers are significantly more bioactive on synapses and microglia than the HMW species from which they are derived. We conclude that conditions that destabilize HMW oA $\beta$ or retard the sequestration of smaller, more bioactive components are important drivers of $\mathrm{A} \beta$ toxicity.

\section{Introduction}

Converging lines of evidence support the concept that diffusible oligomers of the amyloid $\beta$-protein $(\mathrm{A} \beta)$ are the principal cytotoxic agents that induce a complex array of downstream effects

\footnotetext{
Received May 26, 2016; revised Sept. 30, 2016; accepted Nov. 3, 2016.

Author contributions: T.Y., S.L., H.X., D.M.W., and D.J.S. designed research; T.Y., S.L., and H.X. performed research; T.Y., D.M.W., and D.J.S. analyzed data and wrote the paper.

This work was supported by National Institute on Aging Grants AG006173 and AG015379 to D.J.S. and AG046275 to D.M.W., and the Marr Family Fund at Brigham and Women's Hospital. The anti-A $\beta$ antibodies 3D6, m266, 263, and 21F12 were a kind gift from Dr. G. Basi, formerly of Elan Pharmaceuticals. We thank Dr. Matthew Frosch for human brain tissues; and Dr. Tiernan T. O'Malley for providing A $\beta 40(\mathrm{~S} 26 \mathrm{C})_{2}$.

The authors declare no competing financial interests.
}

on neurons, microglia, astrocytes, and cerebral microvessels in Alzheimer's disease (AD) (Walsh and Selkoe, 2007). Because A $\beta$ accumulation in the human brain occurs extracellularly for the most part, it is assumed that the soluble oligomers bind to the plasma membranes of these diverse cell types and trigger transmembrane signaling events that lead to the intracellular changes that occur in $\mathrm{AD}$. Given the importance of this early triggering

Correspondence should be addressed to either Dr. Dennis J. Selkoe or Dr. Dominc M. Walsh, Ann Romney Center for Neurologic Diseases, Department of Neurology, Brigham and Women's Hospital, Harvard Medical School, Boston, MA 02115. E-mail: dselkoe@partners.org or dwalsh@partners.org.

D0I:10.1523/JNEUROSCI.1698-16.2016

Copyright $\odot 2017$ the authors $\quad 0270-6474 / 17 / 370152-12 \$ 15.00 / 0$ 
Table 1. The epitopes of antihuman mouse $\lg G \mathrm{mAbs}$

\begin{tabular}{|c|c|c|c|c|}
\hline Antibody & Species origins & Antigen & Epitope & Source \\
\hline 266 & $\lg G 1$ mouse & $A \beta(13-26)$ & $A \beta(13-26)$ & Elan Pharmaceuticals \\
\hline $2 \mathrm{G3}$ & $\lg G 2 \mathrm{a}$ mouse & $A \beta(33-40)$ & $A \beta 33-40$ with free Val40 & Elan Pharmaceuticals \\
\hline $21 \mathrm{~F} 12$ & IgG2a mouse & $A \beta(33-42)$ & $A \beta 33-42$ with free lle42 & Elan Pharmaceuticals \\
\hline 3D6 & $\lg G 2 b$ mouse & $A \beta(1-5)$ & $A \beta 1-5$ with free Asp1 & Elan Pharmaceuticals \\
\hline $1 C 22$ & Mouse & Aggregated (A $\beta(1-40)$ S26C)2 & $A \beta$ oligomers & D.M.W. laboratory \\
\hline $6 \mathrm{E} 10$ & $\lg G 1$ Mouse & $A \beta(1-16)$ & $A \beta(3-8)$ & Biolegend \\
\hline
\end{tabular}

action in $\mathrm{AD}$ pathogenesis, one needs to understand the characteristics of those oligomers that are most bioactive. This unresolved question has direct implications for selecting the most efficacious anti-A $\beta$ therapeutic agents.

Soluble $\mathrm{A} \beta$ oligomers of a wide range of sizes appear to be in a complex equilibrium with the $8 \mathrm{~nm}$ fibrils of $\mathrm{A} \beta$ that are deposited in insoluble amyloid plaques. There has been considerable debate about which $\mathrm{A} \beta$ assemblies are most responsible for inducing cytotoxicity. The vast majority of studies attempting to address the bioactive properties of $A \beta$ oligomers have used synthetic assemblies of one defined peptide length that are aggregated in vitro and applied under nonphysiological concentrations and conditions. In contrast, we have focused our work on the analysis of natural, aqueously soluble oligomers extracted directly from the affected cerebral cortex of patients with clinically and neuropathologically confirmed AD. Here, we use nondenaturing gel filtration to separate various sizes of soluble assemblies and assess their relative potencies in perturbing both synaptic and microglial function in normal rodent hippocampus. We find that the great majority of aqueously extractable oligomers are large in size and generally have very low bioactivity on the hippocampus, both in vitro and in vivo. However, if these large assemblies are first incubated in mildly alkaline aqueous buffer for $1-2 \mathrm{~d}$, they dissociate in considerable part to smaller oligomers that are much more bioactive and can inhibit synaptic plasticity, alter cellsurface receptor levels, and induce a microglial inflammatory response. The demonstration of this equilibrium between large, relatively inactive assemblies and small, potently cytotoxic oligomers from human brain has implications for the role of amyloid plaques in the pathogenesis of cellular dysfunction in $\mathrm{AD}$.

\section{Materials and Methods}

Human brain homogenates. Frozen cerebral cortices (stored at $-80^{\circ} \mathrm{C}$ ) were provided by Dr. M. Frosch (Massachusetts ADRC Neuropathology Core, Massachusetts General Hospital, Boston) under institutional review board-approved protocols. Frozen samples of temporal or frontal cortex ( $1 \mathrm{~g})$ were allowed to thaw on ice, chopped into small pieces with a razor blade, and then homogenized with 25 strokes of a Dounce homogenizer (Fisher) in $4 \mathrm{ml}$ ice-cold $20 \mathrm{~mm}$ Tris $\mathrm{HCl}, \mathrm{pH}$ 7.4, containing $150 \mathrm{~mm} \mathrm{NaCl}$ (TBS) and protease inhibitors. This TBS-soluble $\mathrm{A} \beta$ was separated from membrane-bound and plaque $\mathrm{A} \beta$ by centrifuging TBS homogenates at $175,000 \times g$ at $4^{\circ} \mathrm{C}$ in a TLA 100 rotor (Beckman Coulter) for $30 \mathrm{~min}$, and the supernatant (referred to as the TBS extract) was aliquoted and stored at $-80^{\circ} \mathrm{C}$. In general, the terms "soluble $\mathrm{A} \beta$ " and "aqueous extract" used herein refer to any forms of $\mathrm{A} \beta$ that remain in this supernatant following ultracentrifugation.

Antibodies and immunoassays. Immunoassays for $\mathrm{A} \beta 1-\mathrm{x}, \mathrm{A} \beta \mathrm{x}-40$, and $A \beta x-42$ were performed on the MesoScale Discovery (MSD) platform as described previously (Yang et al., 2013, 2015). Monoclonal antibody $(\mathrm{mAb}) \mathrm{m} 266$, which recognizes an epitope within $\mathrm{A} \beta 13-26$, was used for capture, and Asp1 (3D6), A $\beta 40$ (2G3), or A $\beta 42$ (21F12) specific antibodies were used for detection (Table 1). All samples and standards were analyzed in duplicate.

Oligomeric forms of $\mathrm{A} \beta$ were captured using our oligomer-preferring $\mathrm{mAb}, 1 \mathrm{C} 22$, and detected using biotinylated 3D6 (Yang et al., 2015).
Standard curves were generated with wild-type (wt) synthetic human $A \beta 1-40$ for the $A \beta 1-x$ and $A \beta x-40$ assays, and wt synthetic $A \beta 1-42$ for the $A \beta x-42$ assay. Amyloid-derived diffusible ligands were prepared from synthetic $\mathrm{A} \beta 1-42$, and size-exclusion chromatography (SEC) was used to isolate the high molecular weight (HMW) component, which served as the calibrant for the oligomer assay (Yang et al., 2015).

SEC. Whole TBS extracts $(250 \mu \mathrm{l})$ or their void volume SEC fractions $(500 \mu \mathrm{l})$ were injected onto either a Superdex $75(10 / 30 \mathrm{HR})$ column or a Superdex 200 (10/300GL) column (GE Healthcare) and eluted at a flow rate of $0.8 \mathrm{ml} / \mathrm{min}$ with $50 \mathrm{~mm}$ ammonium acetate, $\mathrm{pH}$ 8.5. The $1 \mathrm{ml}$ fractions were collected; $0.5 \mathrm{ml}$ of this material was used for ELISA, and the other $0.5 \mathrm{ml}$ was lyophilized and used for Western blotting (Shankar et al., 2011). Samples were electrophoresed on 26 -well, $4 \%-12 \%$ polyacrylamide Bis-Tris gels using MES running buffer (Invitrogen), and proteins were transferred to $0.2 \mu \mathrm{m}$ nitrocellulose filters, the filters microwaved, and $A \beta$ detected using a mixture of mAbs $2 \mathrm{G} 3,21 \mathrm{~F} 12$ (each at $1 \mu \mathrm{g} / \mathrm{ml}$ ) and $0.5 \mu \mathrm{g} / \mathrm{ml}$ of mAb 6E10 (Table 1). Membranes were rinsed and incubated for $1 \mathrm{~h}$ with fluorescein-conjugated goat anti-rabbit or anti-mouse IgG (1:5,000; Invitrogen), and bands visualized using a LiCor Odyssey Infrared System.

Preparation of preincubation and postincubation samples. AD TBS extracts were prepared as described above and stored as $1 \mathrm{ml}$ aliquots at $-80^{\circ} \mathrm{C}$. To generate postincubation samples, aliquots were thawed and chromatographed on a Superdex 75 10/30HR column eluted with $50 \mathrm{~mm}$ ammonium acetate, $\mathrm{pH} 8.5$, and fractions 6 and 7 were pooled and incubated in sealed tubes at $37^{\circ} \mathrm{C}$ for $2 \mathrm{~d}$. At the end of this period, these "postincubated samples" were used immediately or stored on ice and used within $6 \mathrm{~h}$. "Preincubated samples" were produced exactly $2 \mathrm{~d}$ after the initiation of the $37^{\circ} \mathrm{C}$ incubation used to generate the postincubation samples: a $1 \mathrm{ml}$ aliquot of AD-TBS extract was thawed and chromatographed just as described above. Fractions 6 and 7 of this SEC run were pooled and used immediately or stored on ice and then used within $6 \mathrm{~h}$. In this way, both the "pre" and "post" samples were available for use and analysis at exactly the same time. For each experiment described in Results, we compared two or more matched pairs of preincubation and postincubation samples in the various bioassays.

Mice. All experiments involving mice were approved by the Harvard Medical School Committee on Animals. Both male and female C57BL/6 mice were used. Animals were housed in a temperature-controlled room on a $12 \mathrm{~h}$ light/ $12 \mathrm{~h}$ dark cycle and had free access to food and water.

Hippocampal slice preparation and electrophysiological recordings. Hippocampal slices were prepared and used as previously described (Li et al., 2013). Briefly, 350- $\mu \mathrm{m}$-thick transverse slices from hippocampus of 6- to 8 -week-old C57BL/6 mice were incubated for $>90 \mathrm{~min}$ in aCSF containing the following (in mM): $124 \mathrm{NaCl}, 2 \mathrm{KCl}, 2 \mathrm{MgSO}_{4}, 1.25 \mathrm{NaH}_{2} \mathrm{PO}_{4}, 2.5$ $\mathrm{CaCl}_{2}, 26 \mathrm{NaHCO}_{3}, 10$ D-glucose, pH 7.4, 310 mOsm. Then slices were submerged beneath continuously perfused aCSF saturated with $95 \%$ $\mathrm{O}_{2} / 5 \% \mathrm{CO}_{2}$. The $1 \mathrm{ml}$ aliquots of an SEC fraction were added to the $9 \mathrm{ml}$ of aCSF to yield a final volume of $10 \mathrm{ml}$ of the slice perfusate for the LTP recordings. A stimulating electrode was placed in the Schaffer collaterals to deliver test and conditioning stimuli, and a borosilicate glass recording electrode filled with aCSF was positioned $200-300 \mu \mathrm{m}$ from the stimulating electrode to record field EPSP in the stratum radiatum of CA1 ( $\mathrm{Li}$ et al., 2013). A protocol that induces LTP lasting $\sim 1.5 \mathrm{~h}$ in wt mice of this genetic background (two consecutive trains $1 \mathrm{~s}$ of stimuli at $100 \mathrm{~Hz}$ separated by $20 \mathrm{~s}$ ) was used. Field potentials were amplified $100 \times$ using a Molecular Devices 200B amplifier and digitized with Digidata 1322A. 
Table 2. $A \boldsymbol{\beta}$ oligomer levels are markedly elevated in aqueous extracts of brains from subjects with $\mathrm{AD}^{a}$

\begin{tabular}{|c|c|c|c|c|c|c|}
\hline Case No. & NPDx & Sex & Age (yr) & Postmortem interval & $\mathrm{A} \beta$ oligomers ELISA (pg/ml) & $A \beta 1-x$ ELISA (pg/ml) \\
\hline Control 1 & Control & Male & 92 & 12 & 0 & $107 \pm 5$ \\
\hline Control 2 & Leukodystrophy & Female & 34 & $<14$ & 0 & $99 \pm 11$ \\
\hline Control 3 & Control & Male & 69 & 24 & $857 \pm 62$ & $75 \pm 7$ \\
\hline Control 5 & Control & Female & 60 & 15 & 0 & $69 \pm 28$ \\
\hline AD1 & $A D$ & Female & 70 & 7 & $9,052,737 \pm 274$ & $1982 \pm 11$ \\
\hline AD2 & $A D$ & Female & 91 & NA & $450,728 \pm 530$ & $91 \pm 22$ \\
\hline AD5 & $A D$ & Male & 86 & $<24$ & $298,979 \pm 347$ & $112 \pm 21$ \\
\hline AD6 & $A D$ & Male & 83 & 7 & $2,698,912 \pm 527$ & $292 \pm 7$ \\
\hline
\end{tabular}

${ }^{a}$ Aqueous extracts were prepared from the brains of subjects with or without neuropathologically confirmed AD and analyzed using the monomer-preferring A 31 -x immunoassay and the $1 C 22-3 D 6$ oligomer-preferring immunoassay. NPDx, Neuropathological diagnosis. $n=2$ for ELISAs (mean \pm SD). NA, not available.

Data were sampled at $10 \mathrm{kHz}$ and filtered at $2 \mathrm{kHz}$. Traces were obtained by pClamp 9.2 and analyzed using the Clampfit 9.2.

Hippocampal slices and measurement of $\beta 2 A R$. Hippocampal slices were sectioned by vibratome at $350 \mu \mathrm{m}$ thickness and then treated under different conditions ( $n=3$ slices per treatment). Slices were collected in ice-cold TBS plus protease inhibitors and then homogenized with polypropylene pestle in $1.5 \mathrm{ml}$ microcentrifuge tubes at least 20 passes. After nutating on ice for $10 \mathrm{~min}$, the homogenate was passed through a $27 \mathrm{G}$ needle 4 times and then centrifuged at $1000 \times g$ for $10 \mathrm{~min}$ to remove nuclei and incompletely homogenized material (P1). The resulting supernatant (S1) was spun at $50,000 \times g$ for $1 \mathrm{~h}$ to obtain a P2 pellet. The supernatant (S2) was defined as the cytosolic fraction. The P2 was subsequently resuspended in TBS plus $1 \%$ Triton X-100 with protease inhibitors and homogenized again with a polypropylene pestle. The suspension was incubated at $4^{\circ} \mathrm{C}$ for $1 \mathrm{~h}$ and then spun at $50,000 \times \mathrm{g}$ for $1 \mathrm{~h}$ to obtain the supernatant (S3), which included synaptosomes. Protein concentrations were determined using the BCA assay. We loaded 20 $\mu \mathrm{g}$ of total protein in each lane, separated on $4 \%-12 \%$ SDS-PAGE, and blotted onto nitrocellulose. The blot was blocked for $1 \mathrm{~h}$ at room temperature, followed by incubation overnight at $4^{\circ} \mathrm{C}$ with antibodies to $\beta 2$-adrenergic receptor (Thermo Scientific) or transferrin receptor (Invitrogen). Membranes were rinsed and incubated for $1 \mathrm{~h}$ with goat antirabbit or mouse IgG (1:10,000; Invitrogen). Blots were scanned and imaged using a Li-Cor Odyssey system.

Synthetic $\mathrm{A} \beta 40(\mathrm{~S} 26 \mathrm{C})_{2}$ dimers, which readily form bioactive assemblies that alter $\beta 2 \mathrm{AR}$ expression (Li et al., 2013), were prepared as described previously (O'Nuallain et al., 2010) and used as a positive control to treat slices.

Immunohistochemistry and image analysis. Mice were killed and perfused first with $10 \mathrm{ml}$ ice-cold HBSS and then $10 \mathrm{ml}$ ice-cold 4\% PFA. Brains were rapidly removed and immersed in $4 \% \mathrm{PFA}$ for $2 \mathrm{~h}$ at $4^{\circ} \mathrm{C}$, and then transferred to $30 \%$ sucrose solution for $48 \mathrm{~h}$. The brains were cut into desired blocks and embedded in OCT, and $14 \mu \mathrm{m}$ cryostat coronal sections were prepared. For immunofluorescence imaging, the sections were incubated with primary antibody (anti-p2ry12 1:500, gift of O. Butovsky, Brigham and Women's Hospital; anti-CD68 1:200, Abcam Ab53444). All images were obtained on a Zeiss LSM 510 confocal microscope with $20 \times / 0.75$ objective. Images obtained for the cell morphology analysis were set at $1024 \times 1024$ pixels and collected in $Z$ stacks for 3D reconstruction. Image analysis was completed in ImageJ. Individual microglia images were selected and isolated manually, converted to binary images, then skeletonized for skeleton analysis or analyzed as a particle for circularity $\left(4 \pi \times[\right.$ Area $\left.] /[\text { Perimeter }]^{2}\right)$, solidity ([Area] $/[$ Convex Area]) and \%CD68/microglia (see Results).

Stereotactic intracerebroventricular injection and assessment of microglial activation. Mice were anesthetized with isoflurane and placed into a stereotactic frame with isoflurane vaporizer attached. The lateral ventricle was located as bregma $-2.5 \mathrm{~mm}$; midline $3.1 \mathrm{~mm}$; dura $-3.7 \mathrm{~mm}$, and samples ( $4 \mu \mathrm{l} \mathrm{each}$ ) were injected at a rate of $\sim 0.8 \mu \mathrm{l} / \mathrm{min}$ using a 25 $\mu \mathrm{l}$ airtight glass Hamilton syringe.

\section{Results}

The large majority of $A \boldsymbol{\beta}$ species found in aqueous extracts of AD brain are HMW but can be dissociated into small oligomers and monomers

TBS extracts were prepared from the frontal cortices of 6 neuropathologically confirmed late-onset $\mathrm{AD}$ patients and 5 non-AD control subjects (Table 2). Extracts were analyzed using $\mathrm{A} \beta$ monomer- and oligomer-preferring immunoassays and by SEC/ Western blotting. Our MSD A $\beta$ “ $1-\mathrm{x}$ ” assay uses mAbs 266 for capture and 3D6 for detection and has a lower limit of quantification of $\sim 16.4 \mathrm{pg} / \mathrm{ml}$ and preferentially recognizes $\mathrm{A} \beta$ monomers (Mably et al., 2015), whereas our MSD oA $\beta$ assay uses the oligomer-preferring mAb 1C22 for capture and then 3D6 for detection and preferentially recognizes $\mathrm{A} \beta$ oligomers, with a lower limit of quantification for amyloid-derived diffusible ligands (synthetic A $\beta 42$ aggregates or ADDLs) of $\sim 18.7 \mathrm{pg} / \mathrm{ml}$ (Yang et al., 2015) (Table 2). Brain extracts from AD cases tended to have higher levels of $\mathrm{A} \beta 1-\mathrm{x}$ monomer than controls (e.g., average values of $\sim 835 \mathrm{pg} / \mathrm{ml} \mathrm{vs} \sim 170 \mathrm{pg} / \mathrm{ml}$ ), but there was overlap, with some control brain extracts having higher monomer levels than certain $\mathrm{AD}$ cases. In contrast, oligomer levels measured using the 1C22-3D6 assay were always markedly higher in $\mathrm{AD}$ extracts than in extracts from aged control brains (e.g., average values of $3,226,123 \mathrm{pg} / \mathrm{ml}$ vs $788 \mathrm{pg} / \mathrm{ml}$ ). Strikingly, no A $\beta$ oligomers were detected in 3 of the 5 control extracts (Table 2). Thus, as we have documented previously, aqueous extracts of $\mathrm{AD}$ brain contain much higher levels of $\mathrm{A} \beta$ oligomers than extracts from non-AD brain (Xia et al., 2009; Yang et al., 2013, 2015), and within $\mathrm{AD}$ brains, the mean levels of oligomers far exceed those of monomers (e.g., 3,226,123 pg/ml vs $835 \mathrm{pg} / \mathrm{ml}$ ).

Because the MSD immunoassays are at least 2 orders of magnitude more sensitive than our Western blotting protocol and the control brains contained only low levels of immunoassaydetectable $\mathrm{A} \beta$, it was not surprising that Western blots of SEC fractions from all control brains failed to detect $\mathrm{A} \beta$ (for a representative Western blot of a control case, see Fig. 1A, left). However, Western blotting of SEC fractions of AD brain extracts, which contained nanogram per milliliter levels of MSDdetectable $\mathrm{oA} \beta$, revealed the presence of HMW $\mathrm{A} \beta$ species that eluted in and near the void volume of a Superdex 75 column (i.e., in fractions 6-8) (Fig. 1A). The Western blot-detectable $\mathrm{A} \beta$ in the void volume fractions migrated after denaturing SDS-PAGE as 2 bands: one centered at $\sim 4 \mathrm{kDa}$ and the other centered at $\sim 7.5 \mathrm{kDa}$. These results indicate that the major $\mathrm{A} \beta$ species detected in $\mathrm{AD}$ extracts are HMW $(\geq 150 \mathrm{kDa})$ but are SDS-labile 


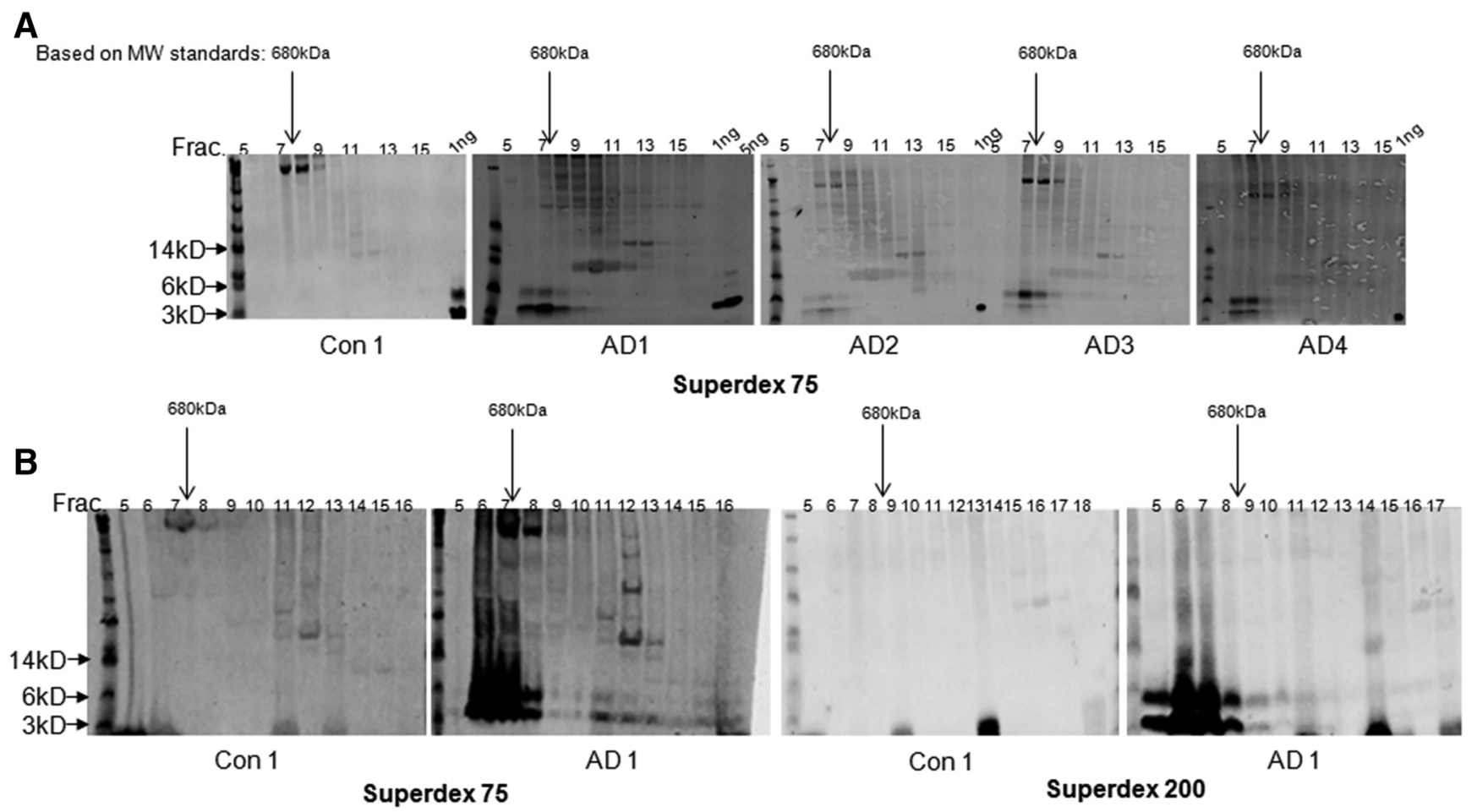

Figure 1. The large majority of $A \beta$ in brain extracts elutes in or near the void volumes upon SEC using Superdex 75 and Superdex 200. A, Human brain extracts (200 $\mu$ l) were chromatographed on a Superdex 75 column, fractions collected, lyophilized, and used for Western blotting with a mix of $2 \mathrm{G3}, 21 \mathrm{~F} 12$, and 6E10. The major A $\beta$-immunoreactive species detected in all 4 AD brain extracts migrated on SDS-PAGE at $\sim 4$ and $\sim 7.5 \mathrm{kDa}$ and were most abundant in SEC fractions within or near the void volume of the Superdex 75 column. $\boldsymbol{B}$, The elution of A $\beta$ species on Superdex 75 versus Superdex 200 was compared by chromatographing aliquots of the same AD sample on the 2 different columns. The majority of the $\sim 4$ and $\sim 7.5 \mathrm{kDa}$ species eluted from both the Superdex 75 and Superdex 200 columns in or near the void. $A, B$, A ladder of MW standards is shown on the left of each gel. Arrows indicate the 14,6 , and $3 \mathrm{kDa}$ standards. The SEC fraction numbers and the position and quantity of $1 \mathrm{ng}, 5 \mathrm{ng}$ synthetic $A \beta 1-40$ standards are indicated at the top of the gels. Arrow indicates the elution of a $680 \mathrm{kDa}$ marker protein from SEC.

Table 3. Fraction numbers for elution of $A D$ brain $A \beta$ on two SEC columns

\begin{tabular}{lcll}
\hline SEC column & $\begin{array}{l}\text { Predicted } \\
(\mathrm{KDa})\end{array}$ & $\begin{array}{l}\text { Typical HMW oA } \beta \text {-containing } \\
\text { fractions }\end{array}$ & $\begin{array}{l}\text { Typical monomer } \\
\text { fractions }\end{array}$ \\
\hline Superdex 75 & $3-70$ & $6-8$ & $11-13$ \\
Superdex 200 & $10-600$ & $5-9$ & $13-14$ \\
\hline
\end{tabular}

Table 4. Volumes and fraction numbers for elution of linear Dextran standards on Superdex 75

\begin{tabular}{lcc}
\hline Dextran standards on Superdex 75 & Eluted volume $(\mathrm{ml})$ & Fraction $\mathrm{no}$ \\
\hline MW $>1 \mathrm{mDa}$ & 8.16 & 6 \\
MW $80 \mathrm{kDa}$ & 8.63 & 7 \\
MW $25 \mathrm{kDa}$ & 9.97 & 8 \\
MW $12 \mathrm{kDa}$ & 12.25 & 10 \\
MW $5 \mathrm{kDa}$ & 14.21 & 12 \\
MW $1 \mathrm{kDa}$ & 15.99 & 14 \\
\hline
\end{tabular}

and, upon denaturing SDS-PAGE, break down to A $\beta$ monomers and what appear to be SDS-stable dimers (McDonald et al., 2015).

In an effort to further characterize the approximate size range of the HMW soluble oA $\beta$ species, we performed SEC using a separation matrix (Superdex 200) that is better able to fractionate higher molecular weight material than is Superdex 75 (Tables 3, 4). Specifically, the manufacturer-reported exclusion limit of Superdex 75 is $\sim 75 \mathrm{kDa}$ for globular proteins, whereas the analogous exclusion limit for Superdex 200 is $\sim 600 \mathrm{kDa}$. When extracts from brain AD1 were chromatographed on a Superdex 200 column, the vast majority of $\mathrm{A} \beta$ eluted in and near the void volume (Fig. $1 B$ ). These data indi- cate that the major portion of $A \beta$ extracted in physiological buffer from $\mathrm{AD}$ cortex consists of very large but still soluble aggregates spanning a mass range from $\sim 150 \mathrm{kDa}$ to $>600$ $\mathrm{kDa}$.

Our earlier work had suggested that the bioactivity of HMW $\mathrm{oA} \beta$ assemblies and of washed amyloid plaque cores from $\mathrm{AD}$ brain tissue was low, and that only oligomer/dimer-rich low molecular weight (LMW) SEC fractions from AD brains consistently impaired synaptic plasticity (Shankar et al., 2008). We therefore examined the potential for disassembling the HMW oA $\beta$ species through dilution and incubation in the mildly alkaline buffer (50 $\mathrm{mm}$ ammonium acetate) used to elute them from the SEC columns. TBS extract of brain AD1 was chromatographed on a Superdex 75 column and $1 \mathrm{ml}$ fractions collected. A portion of each fraction was lyophilized and analyzed by Western blot (Fig. $2 A$, left). The remainder of fraction 6 (void volume) was incubated at $37^{\circ} \mathrm{C}$ for $2 \mathrm{~d}$. After incubation, fraction 6 was rechromatographed on the same Superdex 75 column (after thorough column washing) (Shankar et al., 2011), and the resultant fractions were collected and analyzed by Western blot. After the $2 \mathrm{~d}$ incubation, the $\mathrm{A} \beta$ that had originally eluted in the void of the first SEC (fraction 6; Fig. 2A, left) had dissociated to lower MW species (fractions 7-14; Fig. $2 A$, right). There was now relatively little oA $\beta$ in the void volume fraction, and most $A \beta$ was detected in fractions $11-14$, where synthetic $A \beta$ dimers and monomers are known to elute (O'Malley et al., 2014; McDonald et al., 2015). ELISA analysis of the individual fractions of the first and second SEC runs produced results that paralleled those obtained by Western blotting (compare Fig. 2A,B). Specifically, when fractions of the first SEC of AD TBS extract were quantified with the 


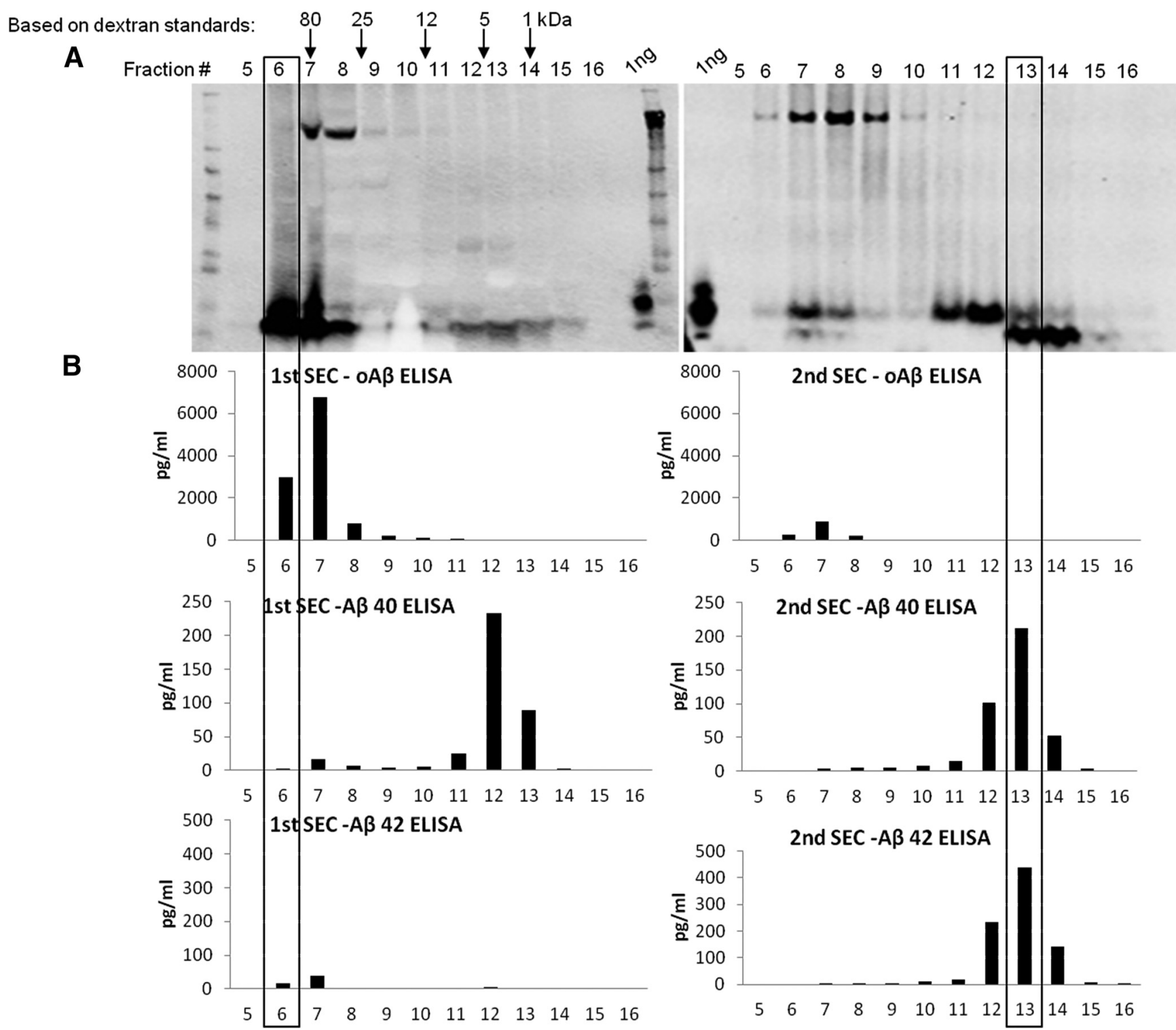

Figure 2. Incubation of soluble HMW $\mathrm{A} \beta \beta$ isolated from human brain by SEC releases lower MW A $\beta$ species. A TBS extract of brain AD1 was chromatographed on a Superdex 75 column, fractions were collected, and a portion of each analyzed by Western blot (mAbs $2 \mathrm{G} 3+21 \mathrm{~F} 12+6 \mathrm{E} 10)\left(\boldsymbol{A}\right.$, left) and by ELISAs ( $\boldsymbol{B}$, left). Fraction 6 from the first SEC (boxed) was incubated at $37^{\circ} \mathrm{C}$ for $2 \mathrm{~d}$ and then chromatographed, and the resultant fractions analyzed by Western blot $(2 \mathrm{G} 3+21 \mathrm{~F} 12+6 \mathrm{E} 10)(\boldsymbol{A}$, right) and by ELISAs (B, right), just as in the parent sample.

oAssay, nanogram levels of $A \beta$ were detected in fractions 6 and 7 , whereas $<50$ pg of $A \beta$ was detected when fractions 6 and 7 were analyzed using the monomer-preferring $\mathrm{A} \beta \mathrm{x}-40$ and $\mathrm{x}-42$ assays (Fig. $2 B$, left panels). The $\mathrm{x}-40$ assay (but not the $\mathrm{x}-42$ assay) also detected small quantities of $A \beta$ in fractions where $A \beta$ monomer is expected to elute (i.e., fractions 11-13). These results are entirely consistent with our quantitative analysis of the whole ADTBS starting extracts (Table 2) and demonstrate that soluble AD brain extracts contain large amounts of HMW oligomers and only small amounts of $A \beta$ monomer, the latter of which appears to terminate largely at Val40, given the specificity of $\mathrm{mAb} 2 \mathrm{G} 3$.

Importantly, when fraction 6 of Case $\mathrm{AD} 1$ (Fig. $2 A, B$, left panels) was analyzed by the oAssay before versus after a $2 \mathrm{~d}$ in vitro incubation, the oligomer signal fell from $10,986 \mathrm{pg} / \mathrm{ml}$ to just $1401 \mathrm{pg} / \mathrm{ml}$, whereas the $\mathrm{x}-42$ monomer signal increased from $68 \mathrm{pg} / \mathrm{ml}$ before to $859 \mathrm{pg} / \mathrm{ml}$ after incubation (Table 5). These results indicate that incubation of $\mathrm{AD}$ brain-derived oligomers in mildly alkaline SEC buffer leads to almost complete
Table 5. The levels of $A \boldsymbol{\beta}$ oligomers decrease, whereas those of $A \boldsymbol{\beta}$ monomers increase, when the void volume fraction of $A D$ brain is incubated at $37^{\circ} \mathrm{C}^{a}$

\begin{tabular}{cccccccc}
\hline & \multicolumn{3}{c}{ Void volume preincubation } & & \multicolumn{3}{c}{ Void volume postincubation } \\
\cline { 2 - 3 } & $x-40$ & $x-42$ & 0ligomers & & $x-40$ & $x-42$ & Oligomers \\
\hline AD1 & 388 & 68 & 10,986 & & 407 & 859 & 1401 \\
AD2 & 105 & 249 & 2079 & & 823 & 4017 & 29 \\
AD3 & 165 & 59 & 984 & & 771 & 104 & 71 \\
AD4 & 19 & 57 & 9711 & & 745 & 1993 & 39 \\
\hline
\end{tabular}

${ }^{a}$ SEC void volume fractions from $4 \mathrm{AD}$ brains were analyzed using $\mathrm{x}-40$ and $\mathrm{x}-42$ monomer-preferring immunoassays, and the 1C22-3D6 oligomer-preferring immunoassay before and after $2 \mathrm{~d}$ incubation at $37^{\circ} \mathrm{C}$.

dissociation of HMW oligomers and the simultaneous appearance of large amounts of $A \beta$ monomer. A second SEC/ELISA analysis of the $2 \mathrm{~d}$-incubated void volume fraction confirmed the results seen with the unfractionated incubated sample (compare Fig. $2 A, B$, right panels; Table 5); that is, the sample now contained little HMW $A \beta$, with the majority of $\mathrm{A} \beta$ now eluting in a manner consistent with $\mathrm{A} \beta$ monomers and dimers (fractions 11- 
14) (Fig. $2 A, B$, right panels). Of interest, the abundant SDSstable dimers observed in fractions 10 and 11 by Western blot (Fig. 2A, right) were not well detected by the oAssay or the $\mathrm{x}-40 / 42$ assays (Fig. 2B, right graphs). This was true regardless of which antibodies we used to construct an oAssay: 1C22, NAB61, or 3D6 for capture, and 3D6, 82E1, or 4G8, respectively, as detector (data not shown). Thus, certain LMW/dimeric oA $\beta$ species are poorly or not detected by oAssays that we had developed and standardized to detect HMW soluble oligomers. Similarly, they were poorly detected by our monomer assays.

As described above for AD1, the TBS extracts of all 4 of our initial AD brains were injected onto Superdex 75 columns, and the void volume fractions obtained were analyzed by ELISAs to quantify $\mathrm{x}-40, \mathrm{x}-42$, and oA $\beta$ (Table 5 ). The void volume fractions of all $4 \mathrm{AD}$ brains behaved similarly, with incubation of $\mathrm{AD}$ brain-derived HMW oligomers in mildly alkaline buffer causing almost complete dissociation of HMW oligomers and the simultaneous appearance of large amounts of $\mathrm{A} \beta$ monomers and dimers. We compared the effects of incubating the initial void volume fraction of AD2 for $6 \mathrm{~h}$ versus $24 \mathrm{~h}$ versus $48 \mathrm{~h}$, and the longer incubations led to much more $\mathrm{HMW}$ oA $\beta$ dissociation to LMW species, as expected (Fig. 3). For subsequent experiments aimed at investigating the bioactivity of the HMW versus dissociated $\mathrm{A} \beta$ species, we set our void volume incubation protocol as a $37^{\circ} \mathrm{C}$ incubation in $50 \mathrm{~mm}$ ammonium acetate, $\mathrm{pH} 8.5$, for $2 \mathrm{~d}$.

\section{LMW A $\beta$ postincubation is more bioactive than fresh HMW $\mathbf{A} \boldsymbol{\beta}$ in inhibiting hippocampal synaptic plasticity}

We next asked which $\mathrm{A} \beta$ assemblies (the original HMW oA $\beta$ species or the LMW oligomers/dimers dissociated from them) are more active in inhibiting synaptic function in the hippocampus, as judged by quantifying the degree of LTP, a widely validated electrophysiological correlate of learning and memory. We applied matched preincubation and postincubation samples of the HMW SEC fractions (fractions 6 and 7) of TBS extracts from each of six AD brains. Using the HMW SEC fraction of Case AD1, both the fresh and postincubation samples depressed LTP, but only the postincubation sample exerted a significant effect (preincubation: $140 \pm 6 \%, n=8$, vs postincubation: $121 \pm 4 \%, n=$ $10 ; p<0.001$ ) (Fig. 4A). The LTP value for the preincubation sample was not significantly different from plain aCSF buffer $(155 \pm 6 \%, n=6)$ used on adjacent slices in the same experiment. When HMW SEC fractions (fractions 6 and 7) of the second brain (AD2) were tested, the preincubation sample had no significant effect on LTP versus aCSF vehicle alone (preincubation: $167 \pm 13 \%, n=6$, vs aCSF $172 \pm 5 \%, n=7 ; p>0.05)$, whereas the postincubation sample significantly inhibited LTP $(141 \pm 5 \%, n=7 ; p<0.01$ ) (Fig. $4 B$ ). Similar results were obtained when HMW SEC fractions 6 and 7 of TBS extracts AD3, $\mathrm{AD} 4, \mathrm{AD} 5$, and AD6 were tested: postincubation samples caused more significant LTP depression than their matched preincubation samples (AD3: pre: $137 \pm 6 \%, n=8$, vs post: $120 \pm 5 \%, n=$ 7; $p<0.001$; AD4: pre: $146 \pm 8 \%, n=4$; vs post: $134 \pm 4 \%, n=$ $4 ; p<0.01$; AD5: pre: $143 \pm 8 \%, n=5$; vs post: $123 \pm 6 \%, n=5$; $p<0.001$; AD6: pre: $153 \pm 9 \%, n=5$; vs post: $132 \pm 8 \%, n=5$; $p<0.001$ ) (Fig. 4C-F). A meta-analysis of all of the multiple preincubation and postincubation samples we ran on the six AD brains showed that the preincubation samples allowed a mean $48 \%$ potentiation of baseline EPSP slope, whereas the postincubation samples allowed a mean potentiation of only $29 \%$ of baseline $(p<0.01)$. Furthermore, we found that this effect on LTP depended on the presence of $\mathrm{A} \beta$ because immunodepletion of $\mathrm{A} \beta$ rescued LTP impairment (data not shown). We conclude that the inhibition of hippocampal synaptic plasticity conferred by smaller oligomers is significantly greater than when the oligomers from the same brain samples were in HMW aggregates.

Paired-pulse facilitation can help reveal whether alterations of synaptic transmission are principally presynaptic. In our previous work (Li et al., 2009), we used a paired-pulse facilitation paradigm with 2 rounds of stimulation and assessed whether soluble oA $\beta$ affected presynaptic release probability. Those experiments indicated that soluble oA $\beta$ in whole AD-TBS extracts did not materially alter presynaptic release probability. Similar experiments performed here showed that there was no alteration of paired-pulse facilitation by the postincubation sample of $\mathrm{AD}$ brain; in addition, input/output curves for both preincubation and postincubation samples did not differ (data not shown).

\section{Postincubation LMW, but not fresh HMW, oA $\beta$ decreases neuronal levels of $\boldsymbol{\beta}$-adrenergic receptors}

Previous studies reported decreases in the levels of $\beta$-adrenergic receptors $(\beta \mathrm{AR})$ and norepinephrine in several regions of $\mathrm{AD}$ brain (Marien et al., 2004; Szot et al., 2006; Manaye et al., 2013). Moreover, human oA $\beta$ applied to rat prefrontal cortex neurons and mouse hippocampal slices has been shown to induce internalization and degradation of $\beta$ AR (Wang et al., 2011; Li et al., 2013). Indeed, we previously reported that, among 8 different monoamine neurotransmitter receptor classes quantified on cultured wt primary neurons, $\beta_{2} \mathrm{AR}$ was the most sensitive to contact with human oA $\beta$ (Li et al., 2013). We therefore examined $\beta_{2} \mathrm{AR}$ protein levels in hippocampal slices exposed to $2 \mathrm{~d}$-incubated SEC void volume fractions versus freshly isolated void volume fractions produced by a separate SEC of the same starting ADTBS extract. After a $4 \mathrm{~h}$ exposure, the levels of $\beta_{2} \mathrm{AR}$ were decreased significantly by the postincubation sample compared with aCSF alone. They were also decreased by treatment with 10 nM of synthetic $A \beta 40(S 26 C)_{2}$ dimers, which we previously found to lower $\beta_{2} \mathrm{AR}$ expression (Li et al., 2013). Quantification documented $65 \%$ and $38 \%$ decreases in $\beta_{2} \mathrm{AR}$, respectively, upon treating the slices with a $10 \mathrm{~nm}$ solution of synthetic (S26C) 2 or a $20 \%$ solution of the human postincubation void volume sample in aCSF (Fig. 5). In contrast, the preincubation samples caused no change (Fig. 5). These differences indicate significantly more reduction of $\beta_{2} \mathrm{AR}$ levels by the $2 \mathrm{~d}$-incubated SEC void volume that contained small oligomers versus the preincubation samples that contained only HMW oA $\beta$.

\section{Small, but not large, soluble $\mathrm{A} \boldsymbol{\beta}$ oligomers stimulate an endogenous microglial response in vivo}

To establish the relative bioactivity of the preincubation and postincubation human samples in vivo, we delivered the two types of $\mathrm{A} \beta$ preparations into healthy, wild-type adult mice by intracerebroventricular microinjection. The preincubation and postincubation samples were again prepared from the same ADTBS extracts. Mice were killed $48 \mathrm{~h}$ after the ipsilateral intracerebroventricular injection, and the contralateral hippocampal/ perihippocampal region was harvested to quantify microglial alteration by immunohistochemical morphology (Fig. 6).

We applied an unbiased microglial morphology method established previously in our laboratory for automated quantifica-

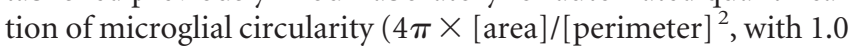
indicating a perfect circle), solidity ([area]/[convex area], with a maximum value of 1.0), number of branches/microglia, and $\%$ CD68/microglia (Xu et al., 2016). Among these four measurements, circularity and solidity describe relative cellular morphology in reference to a perfect circle or convex shape. Microglia 

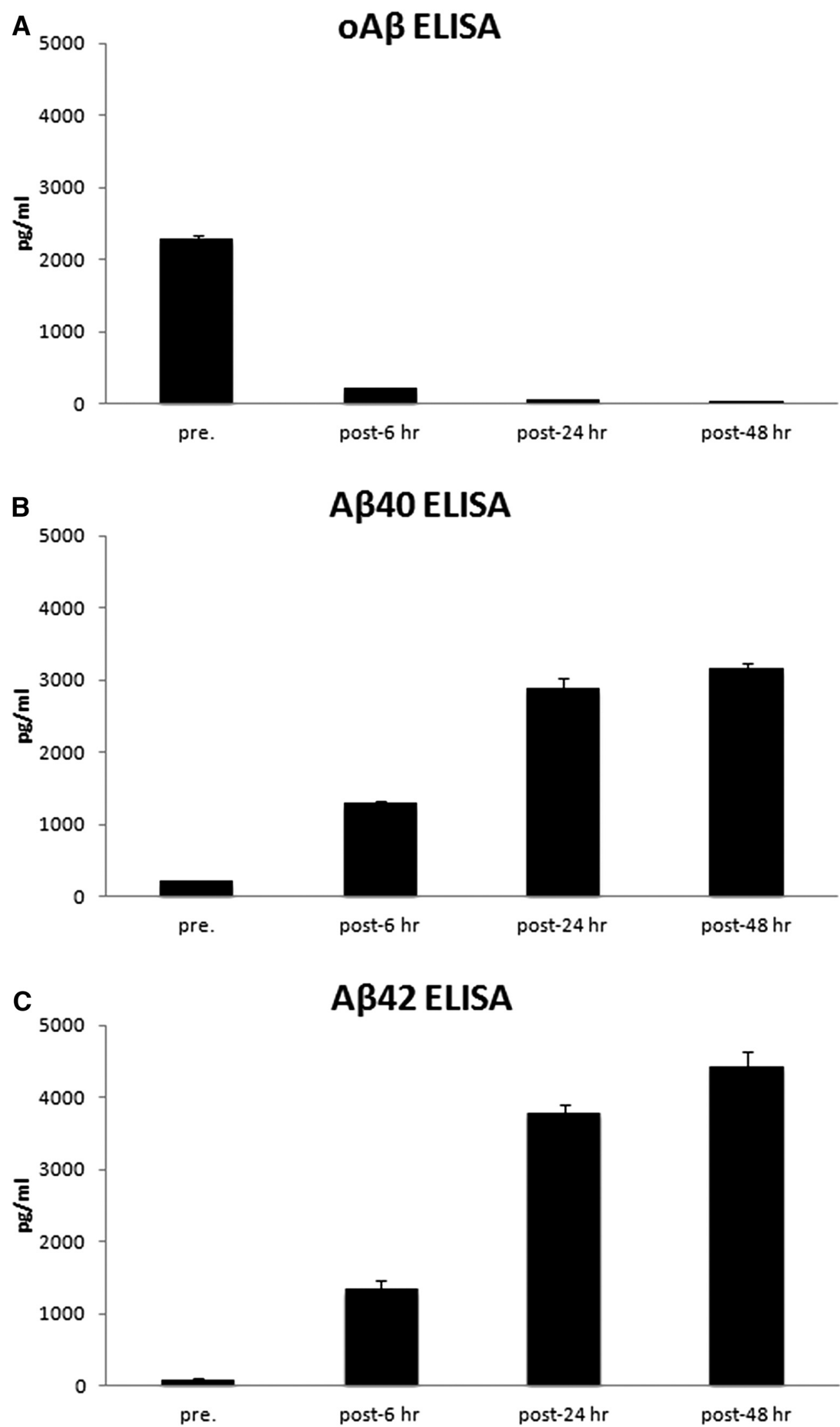

Figure 3. ELISA analyses revealed the time-dependent dissociation of void volume $0 A \beta$ from AD brain. Aliquots ( $300 \mu l$ ) of the SEC void volume fraction (fraction 6 ) of $A D 2$ extract were incubated at $37^{\circ} \mathrm{C}$ for $0,6,24$, or $48 \mathrm{~h}$ and then snap frozen in liquid nitrogen and stored at $-80^{\circ} \mathrm{C}$ pending analysis. Samples were thawed on ice and analyzed using the oligomer-preferring $(A)$ or the monomer-preferring $A \beta x-40(B)$ and $A \beta x-42(C)$ immunoassays. 
A

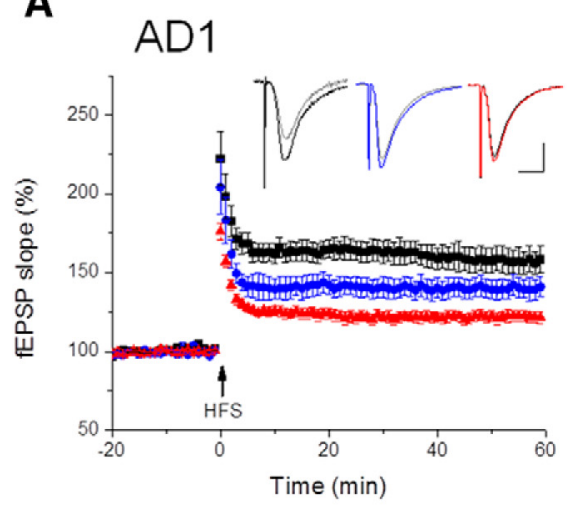

D

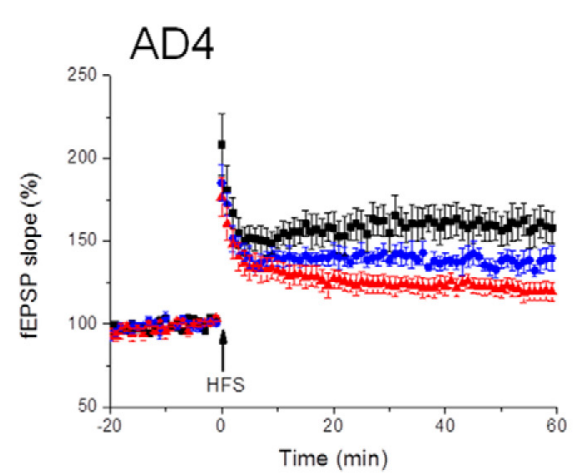

B

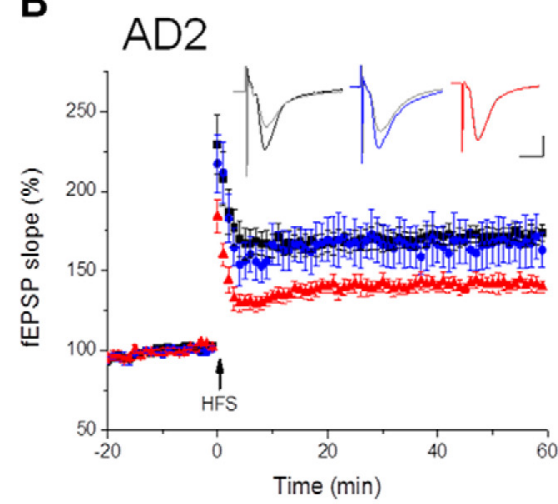

E

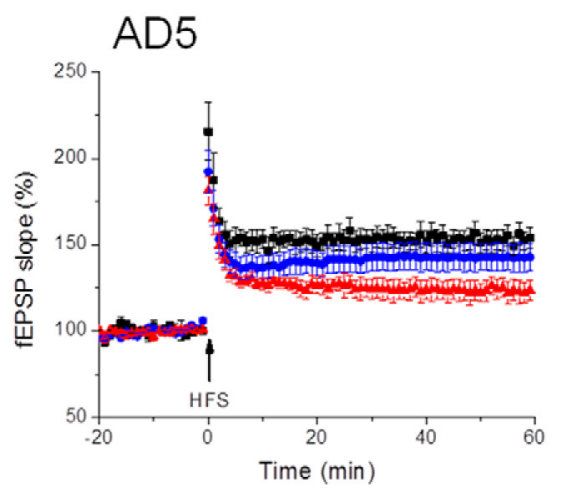

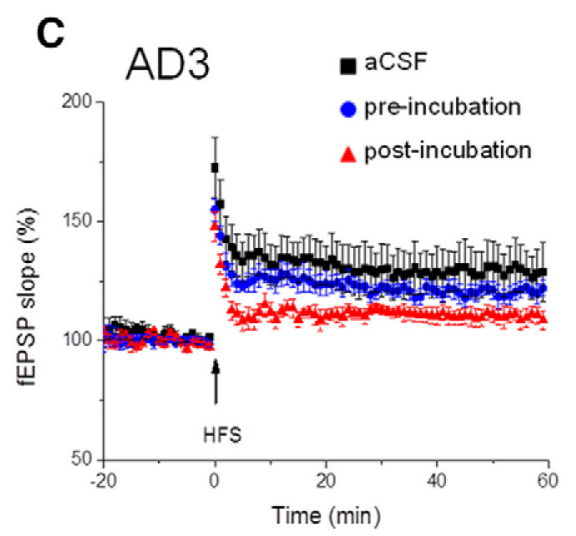

$\mathbf{F}$

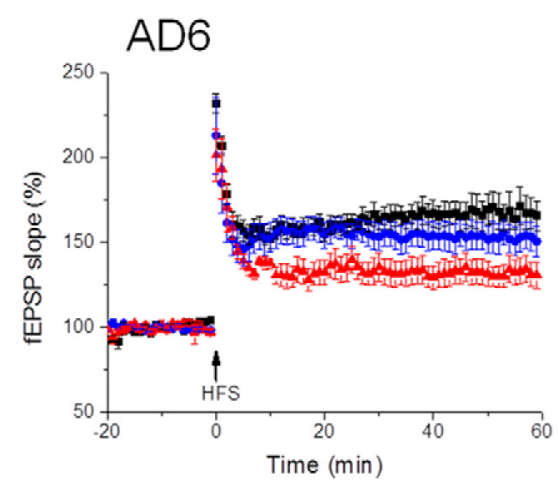

Figure 4. Incubation of HMW oA $\beta$ releases A $\beta$ species that can inhibit hippocampal LTP. SEC void volume fractions from AD1-AD6 (A-F) were each tested for their effect on hippocampal LTP before in vitro incubation (blue circles, $n=8$ ) or after incubation at $37^{\circ} \mathrm{C}$ for $2 \mathrm{~d}$ (red triangles, $n=10$ ). LTP values in the text are the EPSP slopes relative to baseline just before HFS ( $100 \%$ ) measured $60 \mathrm{~min}$ after a high-frequency stimulus (HFS, arrows). Two-tailed Student's $t$ test and one-way ANOVA were used to determine statistical significance.

A

\section{Synaptosome}

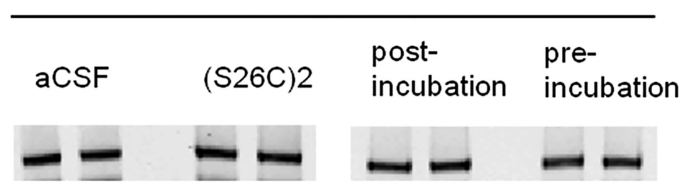

TfR

188-

$98-$

B2AR 62-

49-
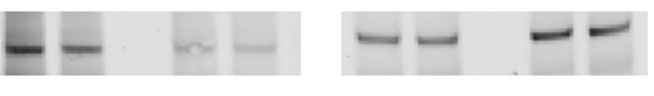

B

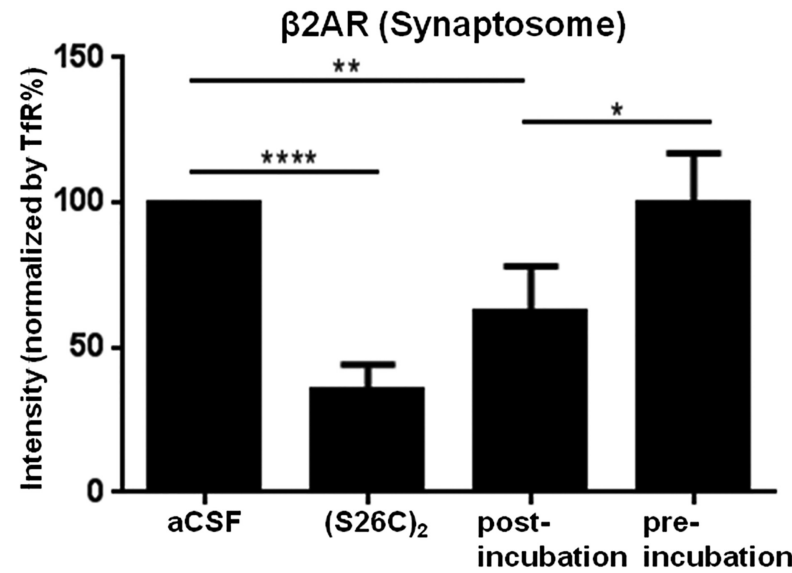

Figure 5. Incubation of HMW OA $\beta$ releases $A \beta$ species that decrease hippocampal $\beta_{2} A R$ levels. Hippocampal slices were exposed for $4 \mathrm{~h}$ to fresh or $2 \mathrm{~d}$-incubated SEC void volume fractions of brain $\mathrm{AD2}$, or aCSF, or $10 \mathrm{~nm}$ of synthetic human $\mathrm{A} \beta(\mathrm{S} 26 \mathrm{C})_{2}$ dimers. $A$, Hippocampal synaptosomes were then prepared and $\beta_{2} A R$ levels quantified by Western blot and the values normalized to transferrin receptor (TfR) protein measured in the same sample. $\boldsymbol{B}$, Summary data from 4 separate Western blots, as exemplified in $\boldsymbol{A}$. Protein levels are normalized based on detection of TfR. Error bars indicate SEM. ${ }^{*} p<0.05 ;{ }^{* *} p<0.01 ;{ }^{* * *} p<0.0001$.

with a more ramified morphology resemble a perfect circle or convex shape less than do microglia with an amoeboid morphology; thus, the former have lower circularity and solidity values. Number of branches/microglia measures the complexity of processes by quantifying total branching points. \%CD68 evaluates the level of a lysosomal marker within microglia, which reflects microglial phagocytic activity. Microglia were immunostained with a recently discovered $\mathrm{mAb}$ to the microglia-specific surface protein P2ry12 (Butovsky et al., 2014). We observed consistent and statistically significant differences in all four measures of microglial morphology in both the cornu ammonis (CA) and dentate gyrus (DG) of hippocampus between mice receiving the preincubation and postincubation samples of the SEC void volume fraction of AD-TBS. Mice receiving the postincubation samples had highly significant increases in contralateral microglial activation (Fig. 6), as shown by higher circularity values (CA: pre $=0.099 \pm 0.013$ vs post $=0.170 \pm 0.026, p<0.0001$; DG: pre $=0.099 \pm 0.012$ vs post $=0.160 \pm 0.022, p<0.0001$ ), higher 
A
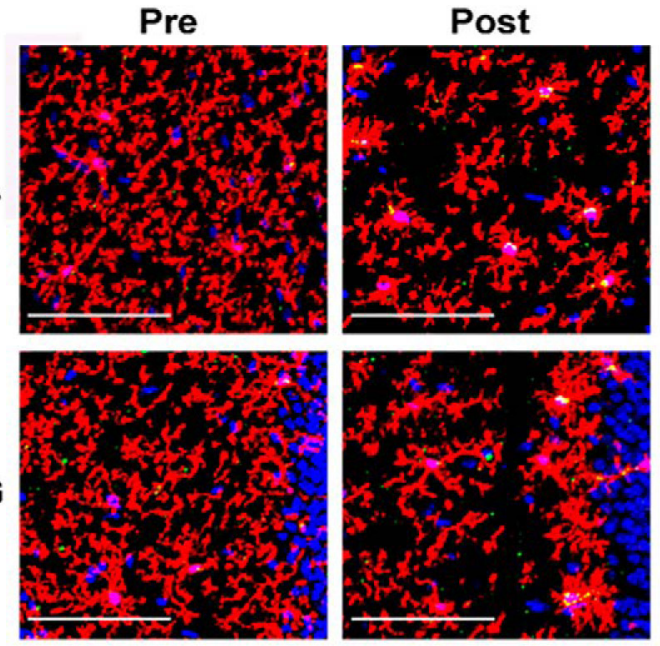

ID Post
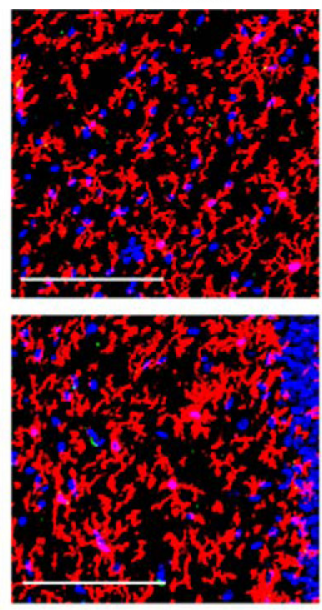

B

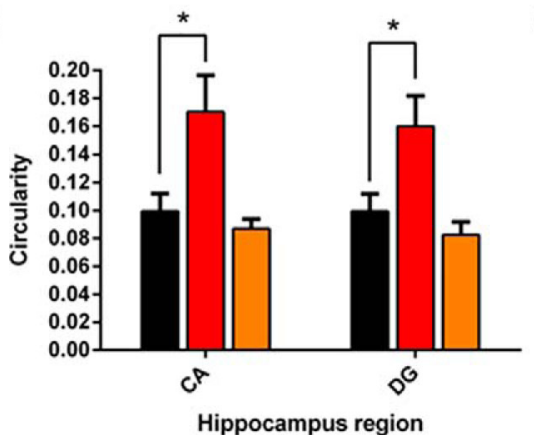

\section{C}

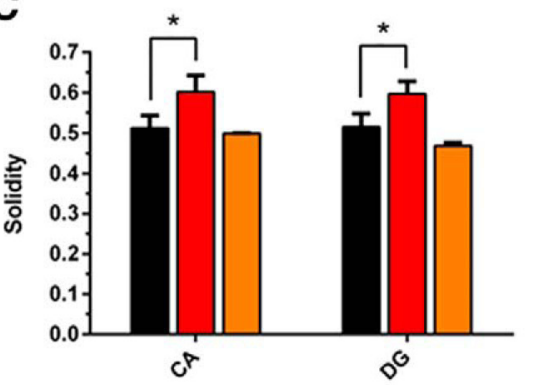

Hippocampus region
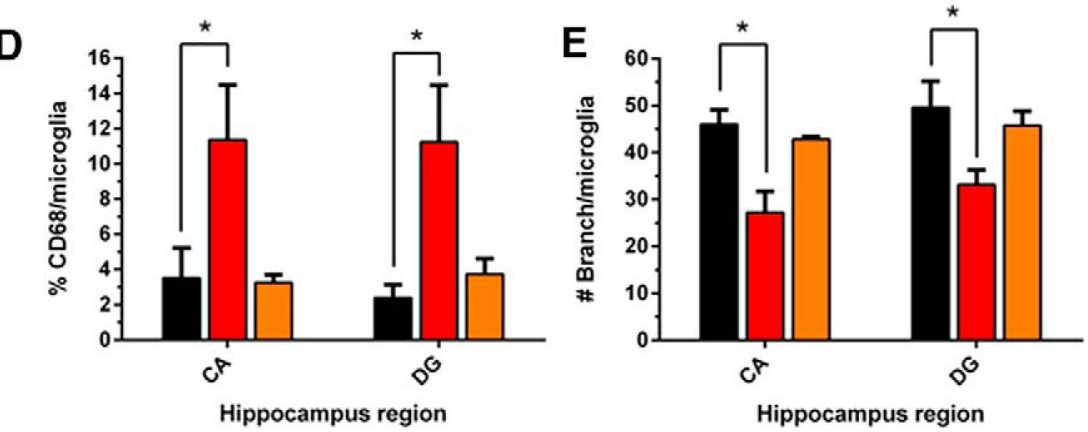

Hippocampus region
Pre-incubation $(\mathrm{N}=6)$

$\square$ Post-incubation ( $\mathrm{N}=7$ )

ID Post-incubation $(\mathrm{N}=2)$

Figure 6. Incubation of HMW $O A \beta$ releases $A \beta$ species that enhance the activation of hippocampal microglia in vivo. The incubated SEC void volume fraction from brain AD1 induced morphological changes in contralateral hippocampal microglia $48 \mathrm{~h}$ after injection into lateral ventricle. $\boldsymbol{A}$, Microglial alterations were analyzed by immunohistochemical morphometry. $\boldsymbol{B}$, The microglia were analyzed by unbiased automated quantification of the following: $\boldsymbol{B}$, circularity $\left(4 \pi \times\right.$ [area]/[perimeter] ${ }^{2}$, with 1.0 indicating a perfect circle); $\boldsymbol{C}$, solidity ([area]/[convex area], with a maximum value of 1.0); (D) \%(D68/microglia; and (E) no. of branches/microglia. Preincubation (black, $n=6$ ), postincubation (red, $n=7)$, and ID postincubation (orange, $n=2$ ) samples were microinjected into wild-type adult mice. Asterisk $\left(^{*}\right)$ indicates statistically significant differences; $p$ values provided in the text.

solidity values $(\mathrm{CA}$ : pre $=0.512 \pm 0.032$ vs post $=0.602 \pm 0.042$, $p<0.01 ;$ DG: pre $=0.515 \pm 0.033$ vs post $=0.597 \pm 0.031, p<$ 0.001 ), lower number of branches/microglia (CA: pre $=46.0 \pm$ 3.1 vs post $=27.2 \pm 4.5, p<0.0001 ;$ DG: pre $=49.6 \pm 5.6$ vs post $=33.2 \pm 3.2, p<0.0001)$, and higher $\%$ CD68/microglia $(\mathrm{CA}:$ pre $=3.51 \pm 1.72$ vs post $=11.37 \pm 3.11, p<0.001 ; \mathrm{DG}$ : pre $=2.39 \pm 0.75$ vs post $=11.24 \pm 3.22, p<0.0001)$.

To confirm that this more activated microglial morphology resulted from the small oligomeric $\mathrm{A} \beta$ species in the postincubation samples, we quantitatively immunodepleted $\mathrm{A} \beta$ from samples using the anti-A $\beta$ mAb, $4 \mathrm{G} 8$ (Fig. 7), and then microinjected the immunodepleted postincubation sample (ID-post) into mice. ID-post induced significantly less intense microglial activation than the same postincubation sample before $\mathrm{A} \beta$ depletion, with all measurements now statistically indistinguishable from that of the preincubation sample, indicating that the oA $\beta$ species were specifically responsible for the effects (Fig. 6).

\section{Discussion}

We and others previously reported that water-soluble extracts of AD brain potently inhibit LTP, alter synaptic form and number, and most importantly, can actually impair memory consolidation in healthy animals in vivo (Shankar et al., 2008; Barry et al., 2011; Freir et al., 2011; Jin et al., 2011; Li et al., 2011; Borlikova et al., 2013; Hu et al., 2014; Klyubin et al., 2014). In all cases, these effects were reversed when $\mathrm{A} \beta$ was removed (Shankar et al., 2008; Barry et al., 2011; Freir et al., 2011; Jin et al., 2011; Li et al., 2011; Borlikova et al., 2013; Hu 

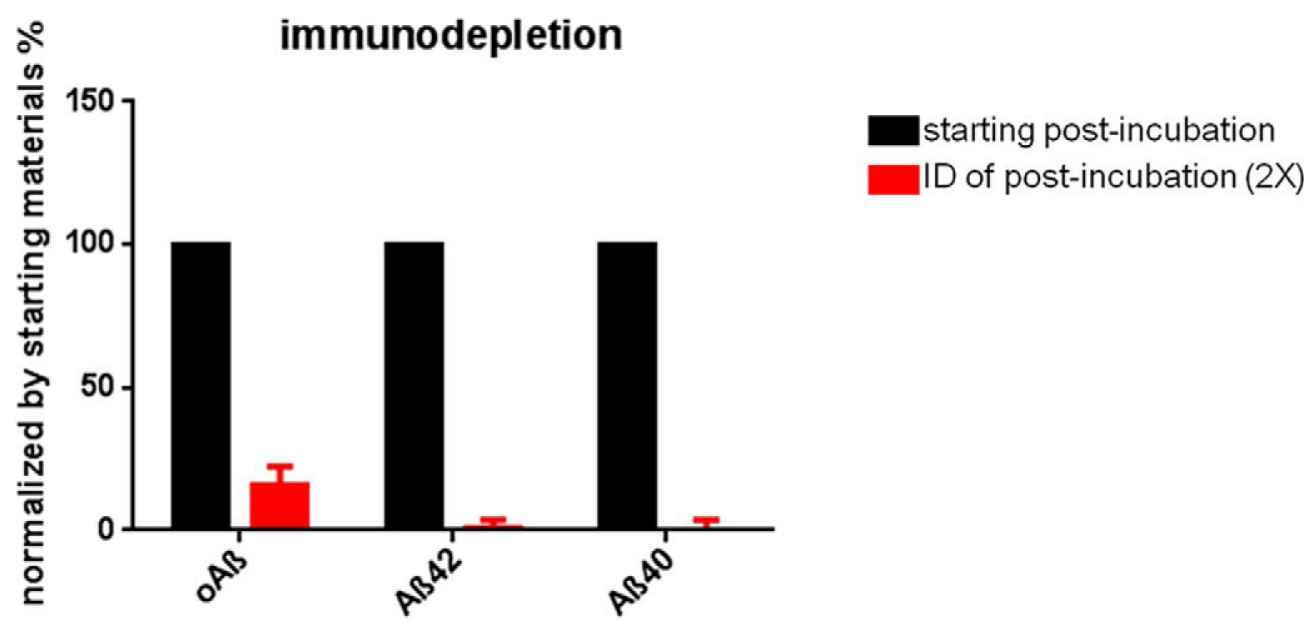

Figure 7. Anti-A $\beta$ antibody, 4G8, quantitatively immunodepletes the void volume fractions of $A \beta$. SEC void volume fractions (fraction 6 ) of $A D$ brain underwent 2 rounds of immunodepletion with the anti-A $\beta \mathrm{mAb} 4 \mathrm{G} 8$. The untreated void volume sample (black bars) and the immunodepleted sample (red bars) were then analyzed using immunoassays for $0 A \beta, A \beta x 402$, and $A \beta x-40.4 G 8$ treatment reduced oligomer levels by $84 \%$ and monomer levels by $99 \%$.

et al., 2014; Klyubin et al., 2014). Many different oligomeric $\mathrm{A} \beta$ species have been described (Walsh and Selkoe, 2004), and there is as yet no consensus about which sized species exist, and can confer cytotoxicity, in the human brain. Immunotherapy with antibodies able to neutralize the toxicity of oligomeric $\mathrm{A} \beta$ species is proposed as a chronic therapy for $\mathrm{AD}$ (Klyubin et al., 2005; Haass and Selkoe, 2007; Walsh and Selkoe, 2007; Lord et al., 2009; Lannfelt et al., 2014; Sevigny et al., 2016), and therefore it is important for improved antibodytarget selection to distinguish between diffusible $\mathrm{A} \beta$ species that are highly bioactive in AD brain and those that are not.

In this study, we used native SEC to separate natural oA $\beta$ aggregates of large versus small size in buffer-soluble extracts of cerebral cortex from clinically and neuropathologically typical late-onset $\mathrm{AD}$ patients. Our SEC results indicate that $\mathrm{HMW}$ oA $\beta$ assemblies comprise the vast majority of soluble $A \beta$ species detectable in aqueous extracts of AD brain. These results are consistent with our prior studies in which we found that $A \beta$ species with apparent molecular weights of $>70 \mathrm{kDa}$ were the predominant forms of $\mathrm{A} \beta$ in aqueous extracts from 33 different $\mathrm{AD}$ brains (McDonald et al., 2015). Similarly, studies using density gradient ultracentrifugation and BN-PAGE analysis (Upadhaya et al., 2012) also reported that the majority of soluble $\mathrm{A} \beta$ in $\mathrm{AD}$ brain extracts exists as HMW assemblies.

We previously observed that immunoprecipitating soluble $\mathrm{A} \beta$ species from $\mathrm{AD}-\mathrm{TBS}$ extracts and then denaturing the precipitates in SDS detergent and separating them by Superdex 75 SEC yields LMW oligomer/dimer-rich fractions that potently impair hippocampal synaptic plasticity, enhance tau phosphorylation at AD-relevant epitopes, and induce neuritic dystrophy in primary neurons (Shankar et al., 2008; Jin et al., 2011). This work left open what role the abundant HMW soluble $\mathrm{A} \beta$ assemblies play in the pathogenesis of AD neurotoxicity, whether as another bioactive form or as a reservoir for the release of LMW oligomers/ dimers that are possibly the principal cytotoxins. Our new data herein strongly support the latter hypothesis. We propose that the noncytotoxic monomer pool (Li et al., 2011) and the LMW $\mathrm{A} \beta$ oligomers are sequestered into increasingly insoluble parenchymal deposits as $\mathrm{AD}$ develops and progresses presymptomatically; the HMW A $\beta$ pool is the intermediate species between monomers and LMW oligomers on the one hand and insolu- ble amyloid plaques on the other, and there is apparently a biochemical equilibrium among these species.

The current dynamic studies of the relative properties of HMW and LMW oA $\beta$ isolated from typical late-onset AD brains offer strong evidence for the hypothesis. With the goal of attempting to disassemble the abundant HMW A $\beta$ species, we subjected HMW A $\beta$ (SEC void volume fractions) to incubation at $37^{\circ} \mathrm{C}$ for $2 \mathrm{~d}$ in $50 \mathrm{~mm}$ ammonium acetate, $\mathrm{pH}$ 8.5. Western blot showed that this incubation of HMW A $\beta$ induced its dissociation into LMW oligomers/dimers and monomers, as shown by a second SEC run that demonstrated a "shift to the right": a marked decrease in the $A \beta$ signals in the void volume fractions and a parallel increase in the $A \beta$ signals in dimer and monomer fractions (Fig. 2A). Our oA $\beta$-selective immunoassay showed that void volume fractions from the first Superdex 75 run produced robust signals, but after the $2 \mathrm{~d}$ incubation, the oA $\beta$ signals in this first void volume fraction were dramatically decreased, whereas the monomeric $A \beta$ signals detectable by a conventional 1-x monomer ELISA were correspondingly increased (Table 2). We confirmed this dissociation of HMW A $\beta$ to LMW/dimeric A $\beta$ and monomers by a second SEC run followed by ELISAs of all fractions (Fig. 2B).

Experiments using freshly isolated void volume HMW oA $\beta$ revealed that this material did not significantly alter hippocampal synaptic plasticity (Fig. 4). This does not mean that the HMW A $\beta$ oligomers have no pathogenic role; rather, our collective experimental findings suggest that they serve as relatively inert reservoirs of small bioactive oligomers. In accord, the postincubation samples contained LMW oligomers/dimers and showed significantly greater LTP inhibition than the void volume before incubation.

The noradrenergic signaling system is known to participate in various forms of learning and memory. $\beta$ AR blockade can impair attention, learning and memory in animals and humans (Cahill et al., 2000; Chamberlain et al., 2006). In AD brain tissue, decreases in the levels of $\beta$ ARs have been reported in several brain regions (Marien et al., 2004; Szot et al., 2006; Manaye et al., 2013), presumably due in part to the observed loss of noradrenergic neurons in the locus ceruleus (Grudzien et al., 2007; Weinshenker, 2008; Manaye et al., 2013). One plausible mechanism for the reduced $\beta A R$ levels in $\mathrm{AD}$ brain is an $\mathrm{oA} \beta$-induced degradation of the receptors (Wang et al., 2011), and this is what we found 
after the application of the postincubation void volume (Fig. 5). The latter, but not the freshly isolated void volume fractions, decreased $\beta 2 A R$ levels in synaptosome fractions of wild-type mouse hippocampal slices.

In an attempt to demonstrate the relative bioactivities in vivo of LMW and HMW oA $\beta$ from the same human brain, we performed intracerebroventricular microinjections into normal adult wt mice. Freshly isolated HMW oA $\beta$ (preincubation) and duplicate void volume fractions isolated from the same AD TBS extract but incubated to facilitate its dissociation to LMW $\mathrm{A} \beta$ species (postincubation) were tested side by side. The postincubation samples induced a significantly higher degree of microglial activation in the contralateral hippocampal region. While the SEC void volume of AD-TBS contains many biomolecules that could change upon prolonged incubation and alter microglia physiology, the fact that the microglial activation was fully prevented by selective immunodepletion with an anti-A $\beta$ monoclonal antibody indicates that the observed effects on microglia in vivo are mediated by LMW forms of soluble $\mathrm{A} \beta$.

How do the data from our biochemical experiments relate to what may occur in the brain tissue of living AD subjects? The relevance of our study to $\mathrm{AD}$ derives from the fact that all of the human brain soluble extracts we analyzed came from patients dying with clinically and neuropathologically typical AD. In this initial study, we focused on available postmortem brains obtained at a late stage of clinical symptomatology. In future studies, we will seek to obtain brain tissue from humans who died at the MCI stage. But it is likely that the resultant data would be similar to our current findings because amyloid pathology (as reflected by neuropathological studies, amyloid PET imaging, and low CSF A $\beta 42$ levels) is already highly abundant at the MCI stage and has been shown to accrue many years or even 2 decades before the appearance of early cognitive symptoms in $\mathrm{AD}$ (see e.g., Bateman et al., 2012; Jack and Holtzman, 2013; Villemagne et al., 2013). These and other studies indicate that, by the MCI clinical stage, $\mathrm{A} \beta$ accumulation is usually advanced. In accord, mean total amyloid plaque number in $\mathrm{AD}$ brains does not rise significantly between the earliest clinical stage and the latest (terminal) stage of symptomatic AD (Hyman et al., 1995). Moreover, in preliminary studies of aqueous extracts of brains from individuals who died at the mild AD stage (e.g., MMSE 24), HMW A $\beta$ oligomers were again the most abundant $\mathrm{A} \beta$ species detected (T. O'Malley and D.M.W., unpublished data).

Our experiments imply that there is a dynamic equilibrium in $\mathrm{AD}$ brain between HMW, largely biologically inactive $\mathrm{oA} \beta$ forms and lower MW, more bioactive forms (e.g., as found in the penumbra of fibrillar amyloid plaques). Evidence for the latter concept comes from APP tg mice, where an oligomer-selective antibody enabled imaging of a penumbra of soluble oligomers surrounding fibrillar plaques (Koffie et al., 2009). The authors showed that neurites were dystrophic and synapses depleted in this zone, but their densities became normal as one measured farther from the fibrillar plaque border. A transition from larger insoluble to smaller more diffusible oA $\beta$ species, presumably similar to those we generated by incubation of HMW soluble fractions, is likely to occur at the outer border of dense-core plaques.

Together, our results indicate that HMW oA $\beta$ are the predominant form of $A \beta$ in the soluble fraction of $A D$ cortex and are far less bioactive than the smaller oligomers to which they can dissociate. Based on the data herein, we hypothesize that $\mathrm{A} \beta$ plaques are composed of both fibrillar $A \beta$ and soluble HMW $\mathrm{oA} \beta$. We speculate that LMW oA $\beta$ can be sequestered into both soluble HMW oA $\beta$ and eventually into increasingly insoluble fibrillar deposits. The HMW oA $\beta$ we describe may thus be an intermediate species between insoluble fibrillar $\mathrm{A} \beta$ and the LMW $\mathrm{oA} \beta$ that we show induces neuronal and microglial toxicity. All of these forms are likely to be in a complex equilibrium in the human brain.

\section{References}

Barry AE, Klyubin I, McDonald JM, Mably AJ, Farrell MA, Scott M, Walsh DM, Rowan MJ (2011) Alzheimer's disease brain-derived amyloidbeta-mediated inhibition of LTP in vivo is prevented by immunotargeting cellular prion protein. J Neurosci 31:7259-7263. CrossRef Medline

Bateman RJ, Xiong C, Benzinger TL, Fagan AM, Goate A, Fox NC, Marcus DS, Cairns NJ, Xie X, Blazey TM, Holtzman DM, Santacruz A, Buckles V, Oliver A, Moulder K, Aisen PS, Ghetti B, Klunk WE, McDade E, Martins RN, et al. (2012) Clinical and biomarker changes in dominantly inherited Alzheimer's disease. N Engl J Med 367:795-804. CrossRef Medline

Borlikova GG, Trejo M, Mably AJ, McDonald JM, Sala Frigerio C, Regan CM, Murphy KJ, Masliah E, Walsh DM (2013) Alzheimer brain-derived amyloid beta-protein impairs synaptic remodeling and memory consolidation. Neurobiol Aging 34:1315-1327. CrossRef Medline

Butovsky O, Jedrychowski MP, Moore CS, Cialic R, Lanser AJ, Gabriely G, Koeglsperger T, Dake B, Wu PM, Doykan CE, Fanek Z, Liu L, Chen Z, Rothstein JD, Ransohoff RM, Gygi SP, Antel JP, Weiner HL (2014) Identification of a unique TGF-beta-dependent molecular and functional signature in microglia. Nat Neurosci 17:131-143. CrossRef Medline

Cahill L, Pham CA, Setlow B (2000) Impaired memory consolidation in rats produced with beta-adrenergic blockade. Neurobiol Learn Mem 74:259266. CrossRef Medline

Chamberlain SR, Müller U, Blackwell AD, Robbins TW, Sahakian BJ (2006) Noradrenergic modulation of working memory and emotional memory in humans. Psychopharmacology 188:397-407. CrossRef Medline

Freir DB, Nicoll AJ, Klyubin I, Panico S, McDonald JM, Risse E, Asante EA, Farrow MA, Sessions RB, Saibil HR, Clarke AR, Rowan MJ, Walsh DM, Collinge J (2011) Interaction between prion protein and toxic amyloid beta assemblies can be therapeutically targeted at multiple sites. Nat Commun 2:336. CrossRef Medline

Grudzien A, Shaw P, Weintraub S, Bigio E, Mash DC, Mesulam MM (2007) Locus coeruleus neurofibrillary degeneration in aging, mild cognitive impairment and early Alzheimer's disease. Neurobiol Aging 28:327-335. CrossRef Medline

Haass C, Selkoe DJ (2007) Soluble protein oligomers in neurodegeneration: lessons from the Alzheimer's amyloid beta-peptide. Nat Rev Mol Cell Biol 8:101-112. CrossRef Medline

Hu NW, Nicoll AJ, Zhang D, Mably AJ, O’Malley T, Purro SA, Terry C, Collinge J, Walsh DM, Rowan MJ (2014) mGlu5 receptors and cellular prion protein mediate amyloid-beta-facilitated synaptic long-term depression in vivo. Nat Commun 5:3374. CrossRef Medline

Hyman BT, West HL, Rebeck GW, Buldyrev SV, Mantegna RN, Ukleja M, Havlin S, Stanley HE (1995) Quantitative analysis of senile plaques in Alzheimer disease: observation of log-normal size distribution and molecular epidemiology of differences associated with apolipoprotein E genotype and trisomy 21 (Down syndrome). Proc Natl Acad Sci U S A 92:3586-3590. CrossRef Medline

Jack CR Jr, Holtzman DM (2013) Biomarker modeling of Alzheimer's disease. Neuron 80:1347-1358. CrossRef Medline

Jin M, Shepardson N, Yang T, Chen G, Walsh D, Selkoe DJ (2011) Soluble amyloid beta-protein dimers isolated from Alzheimer cortex directly induce Tau hyperphosphorylation and neuritic degeneration. Proc Natl Acad Sci U S A 108:5819-5824. CrossRef Medline

Klyubin I, Walsh DM, Lemere CA, Cullen WK, Shankar GM, Betts V, Spooner ET, Jiang L, Anwyl R, Selkoe DJ, Rowan MJ (2005) Amyloid beta protein immunotherapy neutralizes Abeta oligomers that disrupt synaptic plasticity in vivo. Nat Med 11:556-561. CrossRef Medline

Klyubin I, Nicoll AJ, Khalili-Shirazi A, Farmer M, Canning S, Mably A, Linehan J, Brown A, Wakeling M, Brandner S, Walsh DM, Rowan MJ, Collinge $\mathrm{J}$ (2014) Peripheral administration of a humanized anti-PrP antibody blocks Alzheimer's disease Abeta synaptotoxicity. J Neurosci 34:6140-6145. CrossRef Medline

Koffie RM, Meyer-Luehmann M, Hashimoto T, Adams KW, Mielke ML, Garcia-Alloza M, Micheva KD, Smith SJ, Kim ML, Lee VM, Hyman BT, Spires-Jones TL (2009) Oligomeric amyloid beta associates with post- 
synaptic densities and correlates with excitatory synapse loss near senile plaques. Proc Natl Acad Sci U S A 106:4012-4017. CrossRef Medline

Lannfelt L, Möller C, Basun H, Osswald G, Sehlin D, Satlin A, Logovinsky V, Gellerfors P (2014) Perspectives on future Alzheimer therapies: amyloid-beta protofibrils: a new target for immunotherapy with BAN2401 in Alzheimer's disease. Alzheimers Res Ther 6:16. CrossRef Medline

Li S, Hong S, Shepardson NE, Walsh DM, Shankar GM, Selkoe D (2009) Soluble oligomers of amyloid beta protein facilitate hippocampal longterm depression by disrupting neuronal glutamate uptake. Neuron 62: 788-801. CrossRef Medline

Li S, Jin M, Koeglsperger T, Shepardson NE, Shankar GM, Selkoe DJ (2011) Soluble Abeta oligomers inhibit long-term potentiation through a mechanism involving excessive activation of extrasynaptic NR2B-containing NMDA receptors. J Neurosci 31:6627-6638. CrossRef Medline

Li S, Jin M, Zhang D, Yang T, Koeglsperger T, Fu H, Selkoe DJ (2013) Environmental novelty activates beta2-adrenergic signaling to prevent the impairment of hippocampal LTP by Abeta oligomers. Neuron 77:929941. CrossRef Medline

Lord A, Gumucio A, Englund H, Sehlin D, Sundquist VS, Söderberg L, Moller C, Gellerfors P, Lannfelt L, Pettersson FE, Nilsson LN (2009) An amyloid-beta protofibril-selective antibody prevents amyloid formation in a mouse model of Alzheimer's disease. Neurobiol Dis 36:425-434. CrossRef Medline

Mably AJ, Liu W, McDonald JM, Dodart JC, Bard F, Lemere CA, O'Nuallain B, Walsh DM (2015) Anti-Abeta antibodies incapable of reducing cerebral Abeta oligomers fail to attenuate spatial reference memory deficits in J20 mice. Neurobiol Dis 82:372-384. CrossRef Medline

Manaye KF, Mouton PR, Xu G, Drew A, Lei DL, Sharma Y, Rebeck GW, Turner S (2013) Age-related loss of noradrenergic neurons in the brains of triple transgenic mice. Age 35:139-147. CrossRef Medline

Marien MR, Colpaert FC, Rosenquist AC (2004) Noradrenergic mechanisms in neurodegenerative diseases: a theory. Brain Res Brain Res Rev 45:38-78. CrossRef Medline

McDonald JM, O’Malley TT, Liu W, Mably AJ, Brinkmalm G, Portelius E, Wittbold WM 3rd, Frosch MP, Walsh DM (2015) The aqueous phase of Alzheimer's disease brain contains assemblies built from approximately 4 and approximately $7 \mathrm{kDa}$ Abeta species. Alzheimers Dement 11:12861305. CrossRef Medline

O'Malley TT, Oktaviani NA, Zhang D, Lomakin A, O’Nuallain B, Linse S, Benedek GB, Rowan MJ, Mulder FA, Walsh DM (2014) Abeta dimers differ from monomers in structural propensity, aggregation paths and population of synaptotoxic assemblies. Biochem J 461:413-426. CrossRef Medline

O’Nuallain B, Freir DB, Nicoll AJ, Risse E, Ferguson N, Herron CE, Collinge J, Walsh DM (2010) Amyloid beta-protein dimers rapidly form stable synaptotoxic protofibrils. J Neurosci 30:14411-14419. CrossRef Medline

Sevigny J, Chiao P, Bussière T, Weinreb PH, Williams L, Maier M, Dunstan R, Salloway S, Chen T, Ling Y, O'Gorman J, Qian F, Arastu M, Li M, Chollate S, Brennan MS, Quintero-Monzon O, Scannevin RH, Arnold HM, Engber T, et al. (2016) The antibody aducanumab reduces Abeta plaques in Alzheimer's disease. Nature 537:50-56. CrossRef Medline
Shankar GM, Li S, Mehta TH, Garcia-Munoz A, Shepardson NE, Smith I, Brett FM, Farrell MA, Rowan MJ, Lemere CA, Regan CM, Walsh DM, Sabatini BL, Selkoe DJ (2008) Amyloid-beta protein dimers isolated directly from Alzheimer's brains impair synaptic plasticity and memory. Nat Med 14:837-842. CrossRef Medline

Shankar GM, Welzel AT, McDonald JM, Selkoe DJ, Walsh DM (2011) Isolation of low-n amyloid beta-protein oligomers from cultured cells, CSF, and brain. Methods Mol Biol 670:33-44. CrossRef Medline

Szot P, White SS, Greenup JL, Leverenz JB, Peskind ER, Raskind MA (2006) Compensatory changes in the noradrenergic nervous system in the locus ceruleus and hippocampus of postmortem subjects with Alzheimer's disease and dementia with Lewy bodies. J Neurosci 26:467-478. CrossRef Medline

Upadhaya AR, Lungrin I, Yamaguchi H, Fändrich M, Thal DR (2012) Highmolecular weight Abeta oligomers and protofibrils are the predominant Abeta species in the native soluble protein fraction of the AD brain. J Cell Mol Med 16:287-295. CrossRef Medline

Villemagne VL, Burnham S, Bourgeat P, Brown B, Ellis KA, Salvado O, Szoeke C, Macaulay SL, Martins R, Maruff P, Ames D, Rowe CC, Masters CL, Masters CL (2013) Amyloid beta deposition, neurodegeneration, and cognitive decline in sporadic Alzheimer's disease: a prospective cohort study. Lancet Neurol 12:357-367. CrossRef Medline

Walsh DM, Selkoe DJ (2004) Oligomers on the brain: the emerging role of soluble protein aggregates in neurodegeneration. Protein Pept Lett 11: 213-228. CrossRef Medline

Walsh DM, Selkoe DJ (2007) Abeta oligomers: a decade of discovery. J Neurochem 101:1172-1184. CrossRef Medline

Wang D, Yuen EY, Zhou Y, Yan Z, Xiang YK (2011) Amyloid beta peptide(1-42) induces internalization and degradation of beta2 adrenergic receptors in prefrontal cortical neurons. J Biol Chem 286:31852-31863. CrossRef Medline

Weinshenker D (2008) Functional consequences of locus coeruleus degeneration in Alzheimer's disease. Curr Alzheimer Res 5:342-345. CrossRef Medline

Xia W, Yang T, Shankar G, Smith IM, She, Y, Walsh DM, Dennis J, Selkoe M (2009) A specific enzyme-linked immunosorbent assay for measuring $\beta$-amyloid protein oligomers in human plasma and brain tissue of patients with Alzheimer disease. Arch Neurol 66:190-199. CrossRef Medline

Xu H, Gelyana E, Rajsombath M, Yang T, Li S, Selkoe D (2016) Environmental enrichment potently prevents microglia-mediated neuroinflammation by human amyloid beta-protein oligomers. J Neurosci 36: 9041-9056. CrossRef Medline

Yang T, Hong S, O’Malley T, Sperling RA, Walsh DM, Selkoe DJ (2013) New ELISAs with high specificity for soluble oligomers of amyloid betaprotein detect natural Abeta oligomers in human brain but not CSF. Alzheimers Dement 9:99-112. CrossRef Medline

Yang T, O’Malley TT, Kanmert D, Jerecic J, Zieske LR, Zetterberg H, Hyman BT, Walsh DM, Selkoe DJ (2015) A highly sensitive novel immunoassay specifically detects low levels of soluble Abeta oligomers in human cerebrospinal fluid. Alzheimers Res Ther 7:14. CrossRef Medline 